\title{
HUBUNGAN TINGKAT KECEMASAN DENGAN HASIL PUKULAN GATE-IN PADA OLAHRAGA WOODBALL
}

\author{
Ogi Agustiar, Kuston Sultoni
}

Program Studi Ilmu keolahragaan

Departemen Pendidikan Kesehatan dan Rekreasi

Fakultas Pendidikan Olahraga dan Kesehatan

Universitas Pendidikan Indonesia, Jl. Dr. Setiabudhi No. 299 Bandung

Email: Tiar.agustiar@gmail.com

\begin{abstract}
Abstrak
Pukulan gate-in dalam olahraga woodball merupakan pukulan yang menentukan hasil akhir dari permainan. Untuk melakukan pukulan gate-in memerlukan mental yang kuat dan didukung tingkat kecemasan yang baik. Tujuan penelitian untuk mengetahui hubungan kedua variabel antara tingkat kecemasan dengan hasil pukulan gate-in. Metode penelitian menggunakan Deskriptif Korelatif dengan pendekatan kuantitatif, teknik pengambilan sampel yaitu purposive sampling dengan jumlah sampel yaitu 15 atlet UKM woodball UPI. Instrumen yang digunakan dalam penelitian ini adalah mengadoptasi dari Kuesioner SCAT (Mackenzie, 2005) dan mengadoptasi dari tes Pukulan Gate-in (Putu, 2015). Hasil analisis data statistik diketahui nilai pearson correlation sebesar 0,906 dengan signifikansi 0,000 . Hal ini menunjukan terdapat hubungan yang signifikan antara tingkat kecemasan dengan pukulan gate-in pada olahraga woodball. ketika atlet mengalami tingkat kecemasan tinggi maka makin tinggi hasil skor pukulan gate-in dan atlet yang mengalami tingkat kecemasan rendah maka makin rendah hasil skor pukulan gate-in. Nilai uji koefesien determinasi sebesar 0,820. Hal ini menunjukan sumbangan tingkat kecemasan sebesar $82 \%$ terhadap pukulan gate-in pada olahraga woodball. Rekomendasi untuk pelatih olahraga woodball harus memperhatikan latihan mental dan tingkat kecemasan atlet, atlet woodball harus terus melatih teknik pukulan lebih baik lagi, seperti halnya teknik pukulan gate-in dan lebih sering bertanding dengan tim-tim woodball dari daerah lain untuk melatih mental dan tingkat kecemasan atlet agar lebih baik lagi.
\end{abstract}

Kata kunci: tingkat kecemasan, pukulan gate-in, woodball

\section{PENDAHULUAN}

Olahraga Woodball merupakan Olahraga Rekreasi yang dimodifikasi dari olahraga golf. Olahraga Woodball baru dikenalkan pertama kali oleh Mr. Ming-Hui Weng and Mr. KuangChu Young pada tahun 1990 di Cina Taipei (Kriswantoro, 2011, hlm 5). "Jumlah negara anggota IWbF hingga tahun 2016 tercatat 44 negara yang tersebar di lima benua. Salah satu dari ke 44 negara tersebut adalah Indonesia.” (IWbF Woodball).

Olahraga Woodball sudah mulai diminati dikarenakan olahraga woodball merupakan olahraga rekreasi yang menyenangkan, banyak kejuaran-kejuaran woodball yang sudah rutin diadakan oleh berbagai daerah di Indonesia dan peralatan untuk bermain woodball harganya terjangkau. Akan tetapi belum adanya pelatihpelatih pada olahraga woodball, masih belum banyaknya lapangan untuk bermain woodball, 
sarana prasarana untuk woodball masih belum tercukupi dan faktor lainnya.

Menurut Kriswantoro (2011, hlm 33) menyatakan "bahwa Teknik pada olahraga woodball dengan menggunakan alat adalah rutinitas preswing dengan alat (mallet), teknik pukulan jarak jauh, pukulan jarak menengah, pukulan jarak dekat, pukulan ke arah gate." olahraga woodball merupakan keterampilan tertutup (close skill) dikarenakan target pada olahraga woodball ini seperti golf yang lingkungannya dapat diprediksi dan mempunyai target yang tetap atau diam.

Menurut Putu (2015, hlm 5) menyatakan bahwa "keterampilan pukulan jarak dekat tidak memerlukan gerakan tubuh yang banyak, serta tidak membutuhkan ayunan mallet yang panjang dan power yang besar saat terjadi impact. Tapi dalam pukulan dekat itu harus bisa mengontrol ayunannya sehingga bisa menempatkan bola dengan baik dan tepat dekat dengan gawang (gate)".

Menurut Kriswantoro (2011, hlm 17) menyatakan bahwa area gawang (gate) pada olahraga woodball melingkar berdiameter 5 meter dengan gawang sebagai pusatnya dan batas antara gawang dengan garis luar yaitu 2 meter. Sudut untuk melakukan pukulan gate-in yaitu pada sudut 450, 900 dan 1350 dengan gawang (gate) sebagai pusatnya.

Pada saat melakukan pukulan bola ke gawang (gate) harus memukul bola dengan jumlah jumlah pukulan yang sedikit dikarenakan untuk pemenang pada saat pertandingan woodball ditentukan oleh jumlah skor yang sedikit. Menurut Putu (2015, hlm 5) menyatakan bahwa "pemain dapat melakukan pukulan sedikit mungkin dari tee off (pukulan awal) hingga gate-in (bola melewati gate)." Akan tetapi untuk melakukan pukulan gate-in, atlet harus bisa mengarahkan ke target dengan tepat dan didukung oleh tingkat kecemasan yang baik. Sayangnya hal tersebut masih belum dicermati betul oleh pelatih-pelatih woodball bahwa atlet woodball harus mempunyai mental yang baik berupa tingkat kecemasan.
Kecemasan adalah suatu perasaan yang sifatnya umum, dimana seseorang merasa ketakutan atau kehilangan kepercayaan diri yang tidak jelas asal maupun wujudnya (Sutardjo Wiramihardja, 2005 dalam Saputra, 2015, hlm 560). Banyak atlet yang mengalami kegagalan dalam berprestasi dikarenakan oleh faktor mental yang kurang dilatih. Pendapat tersebut diperkuat oleh Harsono (1988) dalam firmansyah (2013, hlm 4) menyebutkan bahwa "kesalahan para pelatih adalah bahwa aspek kesehatan mental yang sangat penting artinya itu sering kali diabaikan atau kurang diperhatikan pada waktu melatih, oleh karena itu dalam mempersiapkan atletnya mereka selalu hanya menekankan pada penguasaan teknik, taktik serta pembentukan keterampilan (skills) yang sempurna". Hal tersebut juga didukung oleh pendapat Gunarsa (2000) dalam Saputra (2015, hlm 560) menyatakan bahwa "Di Indonesia aspek psikologis belum banyak dipelajari dan diteliti sedangkan aspek fisik atlet telah banyak dipelajari." Akan tetapi Menurut Gunarsa (2004) dalam Yulianto (2006, hlm 1) menyatakan bahwa "Atlet yang mempunyai kondisi fisik yang bagus dan prima belum tentu menghasilkan prestasi yang gemilang kalau tidak didukung oleh mental ataupun kondisi psikis yang baik. Tapi jika atlet tersebut tidak memiliki mental yang baik juga, atlet tersebut akan susah bersaing untuk mencapai prestasinya."

Kecemasan juga berhubungan dengan pukulan gate-in pada olahraga woodball. Adapun hubungan antara tingkat kecemasan saat melakukan free throw pada olahraga bola basket dan hubungan tingkat kecemasan saat melakukan penalty pada olahraga sepakbola dan futsal.

Maka dari itu, dengan adanya kaitan antara tingkat kecemasan terhadap keberhasilan seorang pemain dalam melakukan pukulan gate-in dalam permainan woodball yang dapat menunjang pencapaian prestasi olahraga. Oleh karena itu, penulis mengambil judul sebagai berikut. "Hubungan Tingkat Kecemasan 
dengan Hasil Pukulan Gate-in pada Olahraga Woodball"

\section{METODE}

Metode penelitian yang digunakan untuk mengetahui Hubungan Tingkat Kecemasan dengan Hasil Pukulan Gate-in pada Olahraga Woodball adalah pendekatan kuantitatif dengan metode penelitian deskriptif korelatif.

Populasi dalam penelitian ini yaitu atlet UKM Woodball UPI Bandung. Jumlah atlet dalam populasi Ukm Woodball adalah 30 orang. Akan tetapi, untuk sampel penelitian yaitu sebanyak 15 orang dari jumlah populasi yang telah disebutkan yaitu atlet UKM Woodball UPI. Pengambilan sampel dalam penelitian ini menggunakan teknik purposive sampling yaitu teknik pengambilan sampel dengan pertimbangan tertentu. Adapun pertimbangan sampel yang dimbil dalam penelitian ini adalah: a) Atlet ukm woodball UPI b) atlet sudah menguasai teknik dasar bermain woodball c) atlet sudah menguasai teknik dasar pukulan gate-in d) atlet sudah pernah mengikuti kejuaran interen ataupun kejuaran nasional woodball. Berdasarkan pertimbangan yang telah ditentukan oleh peneliti maka sampel untuk penelitian ini berjumlah 15 atlet UKM Woodball UPI.

Instrumen yang digunakan untuk mengukur tingkat kecemasan yaitu Kuesioner Sport Competition Anxiety Test (SCAT). Peneliti mengadopsi kuesioner dari buku Mackenzie (2005, hlm 213). Adapun langkah - langkah pengembangan kuesioner tersebut yaitu dengan menguji validitas kuesioner yang telah dikembangkan berjumlah 15 butir soal. 10 butir soal mengukur simptom yang berhubungan dengan kecemasan, contohnya yaitu pertanyaan no $2,3,5,6,8$,
9, 11, 12, 14, 15 dan 5 butir soal tidak dinilai (skor nol), contohnya yaitu pertanyaan no $1,47,10,13$. Kuesioner ini sudah diterjemahkan dalam Bahasa Indonesia dan sudah valid dengan nilai Realibilitas 0,714 maka instrumen ini sudah raliabel dan valid untuk digunakan penelitian.

Sedangkan instrumen yang digunakan untuk mengukur keterampilan pukulan gate-in mengacu pada isntrumen parking dan pukulan gate-in Putu (2015). Peneliti mengadopsi instrumen dari Tesis Putu (2015) yang sudah memiliki nilai Validitas sebesar 0,830 dan nilai Reliabilitas sebesar 0,905 . Maka instrumen ini sudah valid dan reliabel untuk digunakan dalam penelitian. Prosedur melakukan pukulan gate-in dengan melakukan tiga posisi bola yaitu dengan posisi 1). sudut 450,2 ). sudut 900 dan 3). sudut 1350.

\section{HASIL DAN PEMBAHASAN}

Nilai Frekuensi kategori tingkat kecemasan atlet Ukm Woodball UPI didapatkan hasil tingkat kecemasan rendah yaitu 1 orang, tingkat kecemasan yang ratarata yaitu 9 orang dan tingkat kecemasan yang tinggi yaitu 5 orang. Dan untuk persentase kategori tingkat kecemasan rendah yaitu $6,7 \%$, tingkat kecemasan ratarata yaitu $60 \%$ dan tingkat kecemasan tinggi yaitu 33,3\%. (Lihat Tabel 1)

\section{Tabel 1. Hasil Kategori Tes Tingkat}

\begin{tabular}{|c|c|c|c|c|c|}
\hline & & $\begin{array}{c}\text { Frequen } \\
\text { cy }\end{array}$ & $\begin{array}{c}\text { Perce } \\
n t\end{array}$ & $\begin{array}{c}\text { Valid } \\
\text { Percent }\end{array}$ & $\begin{array}{c}\text { Cumulati } \\
\text { ve } \\
\text { Percent }\end{array}$ \\
\hline \multirow{4}{*}{ Valid } & Rendah & 1 & 6.7 & 6.7 & 6.7 \\
\hline & rata-rata & 9 & 60.0 & 60.0 & 66.7 \\
\hline & Tinggi & 5 & 33.3 & 33.3 & 100.0 \\
\hline & Total & 15 & 100.0 & 100.0 & \\
\hline
\end{tabular}


Asmadi (2008, hlm 47) membagi tingkat kecemasan menjadi tiga tingkat yaitu Tingkat kecemasan ringan. Kecemasan ringan mempunyai karakteristik berhubungan dengan ketegangan dalam peristiwa sehari-hari, kewaspadaan meningkat, persepsi terhadap lingkungan meningkat, sesekali nafas pendek, nadi dan tekanan darah meningkat sedikit, gejala ringan pada lambung, muka berekrut, serta bibir bergetar, tidak dapat duduk tenang, remor halus pada tangan. Tingkat kecemasan sedang. Kecemasan sedang mempunyai karakteristik sering nafas pendek, nadi ekstra sistol dan tekanan darah meningkat, mulut kering, anoreksia, diare/konstipasi, sakit kepala, sering berkemih, dan letih, gerakan tersentaksentak, terlihat lebih tegas, bicara banyak dan lebih cepat, susah tidur, dan perasaan tidak aman. Tingkat kecemasan berat. Kecemasan berat mempunyai karakteristik: nafas pendek, nadi dan tekanan darah naik, berkeringat dan sakit kepala, penglihatan kabur, serta tampak tegang, perasaan terancam meningkat dan komunikasi menjadi terganggu (verbalisasi cepat).

Tabel 2. Hasil Kategori Tes Pukulan Gate-in kategori gate-in

\begin{tabular}{|r|r|r|r|r|}
\hline & Frequency & Percent & \multicolumn{1}{|c|}{$\begin{array}{c}\text { Valid } \\
\text { Percent }\end{array}$} & $\begin{array}{r}\text { Cumulativ } \\
\text { e Percent }\end{array}$ \\
\hline $\begin{array}{r}\text { sangat } \\
\text { baik }\end{array}$ & 1 & 6.7 & 6.7 & 6.7 \\
Baik & 4 & 26.7 & 26.7 & 33.3 \\
Cukup & 4 & 26.7 & 26.7 & 60.0 \\
Kurang & 6 & 40.0 & 40.0 & 100.0 \\
Total & 15 & 100.0 & 100.0 & \\
\hline
\end{tabular}

Pada Tabel 2 di atas diketahui nilai rekuensi Kategori pukulan gate-in atlet Ukm Woodball UPI didapatkan hasil kategori sangat baik yaitu 1, kategori baik yaitu 4 orang, kategori cukup yaitu 4 orang, kategori kurang yaitu 6 orang dan kategori sangat kurang yaitu 0. Dan untuk persentase kategori pukulan gate-in sangat baik yaitu $6,7 \%$, baik yaitu $26,7 \%$, cukup $26,7 \%$ dan kurang yaitu $40 \%$.

Untuk membuktikan hipotesis awal dalam penelitian ini maka selanjutnya dilakukan uji hipotesis menggunakan correlation bivariate karena dalam penelitian ini menghubungkan dua variable dengan menghubungkan antara tingkat kecemasan dengan hasil pukulan gatein pada olahraga woodball.

Tabel 3. Hasil Uji Korelasi Tes Tingkat

Kecemasan dengan Pukulan Gate-in

\begin{tabular}{|ll|l|l|}
\hline \multirow{5}{*}{ Kecemasan } & Kecemasan & Gatein \\
& Pearson & 1 & $.906^{* *}$ \\
& Correlation & & \\
& Sig. (2-tailed) & & .000 \\
& $\mathrm{~N}$ & 15 & 15 \\
gatein & Pearson & $.906^{* *}$ & 1 \\
& Correlation & & \\
& Sig. (2-tailed) & .000 & \\
& $\mathrm{~N}$ & 15 & 15 \\
\hline
\end{tabular}

Dilihat dari tabel 3 hasil output uji korelasi data diketahui nilai sig 0.000 , maka dapat diambil kesimpulan Ho ditolak. Sedangkan nilai pearson correlation sebesar 0.906 menunjukkan memiliki hubungan yang signifikan. Keputusan dai hasil diatas yaitu Pearson Correlation $=0,906, \mathrm{p}=0,000$. Maka H0 ditolak. Hal ini menunjukkan terdapat hubungan yang signifikan antara tingkat kecemasan dengan pukulan gate-in pada olahraga woodball. Makin tinggi tingkat kecemasan makin tinggi juga hasil skor pukulan gate-in pada olahraga woodball dan makin rendah tingkat kecemasan makin rendah juga hasil skor pukulan gate-in pada olahraga woodball.

Koefisien Determinasi (r2) merupakan cara untuk mengetahui beasar kecilnya sumbangan variable bebas terhadap variable terikat. Koefisien determinasi dapat dihitung dengan rumus: 
Koefisien determinasi tingkat kecemasan terhadap pukulan gate-in pada olahraga woodball adalah adalah $82 \%$, sisanya $18 \%$ dipengaruhi oleh faktor lain.

Penelitian ini bertujuan untuk mencari hubungan antara tingkat kecemasan dengan pukulan gate-in pada olahraga woodball. Selain dari faktor kecemasan atlet yang mengakibatkan hasil pukulan kurang baik, adapun faktor lain yang mengakibatkan pukulan gate-in atlet woodball UPI yaitu faktor jarak dan penempatan bola saat melakukan tes cukup sulit, keadaan atau situasi lapangan, fisik atlet yang lelah, atlet yang belum menguasai teknik pukulan gate-in, peralatan yang digunakan seperti Malet dan bolanya, dan faktor-faktor yang lainnya. Hal tersebut didukung oleh pendapat Pesurnay (2000) dalam Podungge (2013, hlm 9) mengatakan bahwa prestasi ditentukan oleh tujuh faktor, dengan tujuh faktor ini maka olahragawan akan mencapai prestasi yang tinggi, ketujuh faktor itu adalah: 1) Keadaan teknis peralatan dan sarana dan prasarana olahraga, 2) Keadaan atau situasi pertandingan, 3) Konsitusi tubuh olahragawan, 4) Keadaan fisik olahragawan, 5) Teknik cabang olahraga, 6) Taktik dan strategi, 7) Keadaan psikis atlet.

Dari hasil analisis penelitian membuktikan bahwa terdapat hubungan yang signifikan antara tingkat kecemasan dengan pukulan gatein pada olahraga woodball. Pada dasarnya untuk olahraga woodball selain memiliki teknik, fisik, taktik yang baik juga harus memiliki mental yang baik.

Menurut Unestahl (1988) dalam Lismadiana (2014, hlm 3) mengemukakan batasan mengenai mental training is a systematic and long-term training to develop and learn to control: (1) behavior, (2) Performance, (3) emotion and moodstate, and (4) bodily processes. Batasan pengertian mental training yang diajukan Unesttahl tersebut menegaskan bahwa mental training mempunyai dampak langsung terhadap tingkah laku, kinerja, emosi dan suasana hati, serta proses-proses jasmaniah. Pada olahraga woodball dibutuhkan pelatihan mental seperti halnya kecemasan. Contoh dilapangan pada saat melakukan pukulan gatein jika pemain tidak mempunyai mental seperti kecemasan yang baik dapat berakibat fatal, karena pada saat melakukan pukulan gate-in dan mengalami tingkat kecemasan yang tinggi, maka akan terjadi gangguan pada fisik atlet. Seperti gangguan pada bagian tubuh dan tangan terasa bergetar, hal tersebut akan berpengaruh saat melakukan pukulan karena gangguan yang terjadi pada tangan. Sehingga mengakibatkan perkenaan bola yang tidak tepat saat melakukan ayunan pukulan dan mengakibatkan bola tidak masuk kegawang (gate) atau bola OB (Out Off Boundary). Karena dalam permainan woodball untuk menetukan jumlah skor yang baik itu pada saat melakukan pukulan gate-in.

Penelitian terlebih dahulu, dimana hasil penelitian-penelitian sebelumnya yang membuktikan bahwa mental sangat berperan penting yaitu atlet yang bisa mengontrol tingkat kecemasan dalam suatu pertandingan akan mendapatkan hasil yang baik. Seperti penelitian oleh Firmansyah (2013) Hubungan kecemasan (anxiety) dengan hasil bertanding pada olahraga woodball. Hasil dari penelitiannya membuktikan bahwa terdapat hubungan yang signifikan antara kecemasan (anxiety) dengan hasil bertanding pada olahraga woodball. Hal ini menunjukan bahwa atlet yang mengalami kecemasan tinggi maka hasil skor bertandingnya tinggi dan atlet yang mengalami kecemasan rendah maka hasil skor bertandingnya rendah. Hasil penelitian ini memperkuat teori yang telah dikemukakan oleh pendapat dari Catty (1973) dalam Kusumajati (2011, hlm 64), yang menyatakan bahwa "Kecemasan berpengaruh besar terhadap penampilan atlet dengan sendirinya akan berpengaruh terhadap prestasinya." dapat menggunakan pilihan kata yang lebih sesuai dengan isi pendahuluan

\section{KESIMPULAN}

Berdasarkan hasil penelitian ini yang telah dibuktikan berdasarkan dari hasil 
pengambilan dan pengolahan data yang telah dilakukan, maka diperoleh hasil sebagai berikut 1).Tes tingkat kecemasan atlet woodball UPI berada dalam kategori tingkat kecemasan rata-rata. 2).Tes pukuluan gate-in atlet woodball UPI berada dalam kategori kurang. 3).Terdapat hubungan yang antara tingkat kecemasan dengan hasil pukulan gate-in pada olahraga woodball, dimana korelasi antara tingkat kecemasan dengan pukulan gate-in terdapat hubungan yang signifikan.

Rekomendasi untuk pelatih olahraga woodball harus memperhatikan latihan mental dan tingkat kecemasan atlet, atlet woodball harus terus melatih teknik pukulan lebih baik lagi, seperti halnya teknik pukulan gate-in dan lebih sering bertanding dengan tim-tim woodball dari daerah lain untuk melatih mental dan tingkat kecemasan atlet agar lebih baik lagi

\section{DAFTAR PUSTAKA}

All Rights Reserved (2014). IWbF (Internasional Woodball Federation). Diakses dari http:// http://www.iwbf-woodball.org/en/8-1.php\#flag32

Asmadi. ( 2008 ), Konsep Dasar Keperawatan, Jakarta : EGC

Dwiariani, Damar Arum (2012). Peran Pelatihan Mental dalam Proses Penurunan Kecemasan Cedera Berulang pada Atlet Putri Bola Basket. (Tesis). Depok. Universitas Indonesia.

Firmansyah, (2013). Hubungan kecemasan (anxiety) dengan hasil bertanding pada olahraga woodball. (Skripsi). Bandung. Universitas Pendidikan Indonesia

Kriswantoro. (2011). Teknik Dasar Bermain Woodball. In $\neg$ donesia. Semarang: Woodball Association

Lismadiana. (2014). Peranan Latihan Mental Dalam Pertandingan Bulutangkis. Universitas Negeri Yogyakarta

Mackenzie, Brian (2005). 101 Performance Evaluation tests. London: Electric Word pcl

Podungge, Risna (2013). Dampak Kecemasan dan Agresifitas Terhadap Prestasi Olahraga Bela Diri. (Jurnal). FIKK UNG

Putu Citra Permana Dewi, dan Sukadiyanto. (2015). Pengembangan Tes Keterampilan Olahraga Woodball Untuk Pemula. (Tesis). Bali. IKIP PGRI Bali.

Saputra, Febriandy tri (2015). Hubungan Antara Kepercayaan Diri Dengan Kecemasan Menghadapi Pertandingan Pada Siswa Skoi Di Samarinda. (jurnal). Samarinda. Universitas Mulawarman Samarinda.

Sugiyono. 2010. Metode Penelitian Pendidikan Pendekatan Kuantitatif Kualitatif dan R\&D. Bandung: Alfabeta

Yulianto, fitri dan H. Fuad Nasroni. (2006). Kepercayaan Diri Dan Prestasi Atlet Tae Kwon Do Daerah Istimewa Yogyakarta. (Jurnal). Universitas Dipenogoro. 